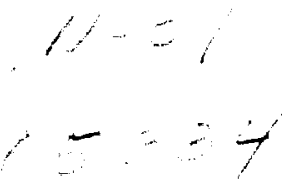

\title{
DESIGN AND USE OF A LARGE-SCALE LIQUID HELIUM CONVERSION SYSTEM
}

\author{
P. N. Knudsen ${ }^{1}$

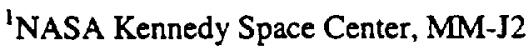 \\ Kennedy Space Center, Florida 32899, USA
}

\begin{abstract}
A large-scale liquid helium (LHe) to high-pressure (HP) gas conversion system has been implemented at the John F. Kennedy Space Center (KSC). Helium is used by the Space Shuttle, Titan, Atlas, and Delta programs for prelaunch processing, during launch count-down, and for postlaunch securing. The first phase of modifications to the Compressor Converter Facility (CCF), operational in April 1998, allowed the facility to accept bulk liquid helium from tanker containers and to off-load the helium at super-critical pressures. The second phase of modifications, planned to be operational by January 2001 , will implement a 227 -cubic-meter $\left(\mathrm{m}^{3}\right)$ on-site liquid helium storage system. This paper describes the design and operation of the current system and discusses the design and implementation for the second phase system.
\end{abstract}

\section{INTRODUCTION}

The design for a modification to the CCF, initiated in September 1995, was motivated by the impending closure of the United States Bureau of Land Management (BLM) Helium Field Operations (HFO) in Amarillo, Texas. Until the enactment of Public Law 104273, the Helium Privatization Act of 1996,1,2,3,4 on October 9, 1996, the BLM HFO [formerly under the supervision of the United States Bureau of Mines (BOM)] had provided KSC with helium by means of high-pressure gas railcars. KSC typically uses approximately 2.0 to 2.8 million standard cubic meters (std $\mathrm{Mm}^{3}$ ) of helium per year ${ }^{5}$ in support of both the Space Transportation System (STS) (namely, the Space Shuttle) and the Cape Canaveral Air Station (CCAS) expendable launch vehicle (ELV) programs (such as the Titan, Atlas, and Delta). At present, the CCF remains the focal point at $\mathrm{KSC}$ that provides helium support to the STS and CCAS ELV programs. 
necting the launch pads and VAB to the CCF. The vessels have since been de-rated to a maximum allowable working pressure (MAWP) of $40.46 \mathrm{MPa}$ to meet section VIII, division 2 of the ASME Boiler and Pressure Vessel Code.

The CCF, originally called the High Pressure Gas and Converter Compressor Facility, was designed by an architect and engineering company in Detroit, Michigan, and the Army Corps of Engineers in 1963 and built by Morrison-Knudsen, Inc. During the Apollo era the CCF housed a high and low pressure liquid nitrogen $\left(\mathrm{LN}_{2}\right)$ conversion system that produced gaseous nitrogen $\left(\mathrm{GN}_{2}\right)$, supplied by a $1893 \mathrm{~m}^{3} \mathrm{LN}_{2}$ storage sphere. This system operated until 1968, when it was deactivated shortly after the "Big-Three" nitrogen plant (off-site of $\mathrm{KSC}$ ) came on-line. The inactive $\mathrm{LN}_{2}$ storage sphere was not removed until 1990. Five 74.6 brake kilowatt (kW) (hereafter referted to as just $\mathrm{kW}$ ) 5 -stage Joy helium compressors, housed in the east end of the CCF, have been used for the Apollo, Skylab, and Space Shuttle programs and are still in service. Each Joy compressor is capable of delivering 12.5 grams per second ( $g / s$ ) of helium, at an induction pressure above $1.38 \mathrm{MPa}$, discharging at $41.4 \mathrm{MPa}$. Prior to the activation of LHe conversion system at the CCF, railcars from the BLM supplied the five Joy compressors (and later, three more Henderson compressors). The compressors either pressurized the helium to the pipeline pressure (presently 39.0 $\mathrm{MPa}$, maximum) and/or pressurized (filled-up) CGT's (to 16.5 or 41.4 $\mathrm{MPa}$ ) and/or railcars (to $25.17 \mathrm{MPa}$ ). The first two $149 \mathrm{~kW}$ 4-stage, high-pressure Henderson compressors were installed in an addition to the CCF east end in 1991 and 1992, respectively, due to the de-rating of the launch pad and VAB storage vessels in 1987. These provided additional capacity to the STS and CCAS ELV programs. The storage vessels were pressurized to 41.4 MPa prior to de-rating the vessels. As a result of the de-rating, approximately $10,200 \mathrm{std}^{3}$ of usable stored helium was forfeited. A third 149$\mathrm{kW}$ high-pressure Henderson, made possible by an under-budget installation of the other two Henderson compressors, was installed in the CCF east end addition in 1994. Each Henderson compressor is capable of delivering 25.0 to $28.5 \mathrm{~g} / \mathrm{s}$ of helium, at a minimum induction pressure of $1.72 \mathrm{MPa}$, discharging at $39.0 \mathrm{MPa}$. These compressors are configured to automatically start-up and shut-down as controlled by a relay control logic system. Both the Joy and Henderson compressors have a "scavenger" compressor (i.e., a separate unit on the Joy compressors and 2 of the 6 cylinders on the Henderson compressors), which removes crankcase blow-by and feeds it back to the first stage. CCF personnel have increased the reliability of the Joy and east end Henderson compressors and have improved their output capacity by 0.8 to $1.6 \mathrm{~g} / \mathrm{s}$ and $1.2 \mathrm{~g} / \mathrm{s}$, respectively. The Henderson compressors are only used to supply helium to the pipeline and are not used to pressurize $41.4 \mathrm{MPa}$ CGT's. Several other modifications and enhancements have been added in past years.

The CCF has a total combined helium output capacity of $140 \mathrm{~g} / \mathrm{s}$ at $39.0 \mathrm{MPa}$ (maximum), filtered and desiccated to meet grade A, MIL-P-27407, as verified and continuously monitored by oxygen, moisture, and hydrocarbon analyzers. The total helium required for a successful Space Shuttle launch can range from 12,700 to $51,000 \mathrm{std} \mathrm{m}^{3}$, with each abort/recycle consuming an additional 20,000 to $22,700 \mathrm{std} \mathrm{m}^{3}$ (approximately). STS operations requires enough helium physically located at KSC 4 days prior to LCD ("call-tostations," the start of LCD, begins at $T-43$ hours) to allow for three launch attempts (i.e., three abort/recycles). Prior to activation of the LHe Conversion System at KSC, this was accomplished by having at least 21 railcars, or approximately $0.15 \mathrm{std} \mathrm{Mm}^{3}$ of helium onsite. At present, this requirement is met by having two (full) LHe tankers and nine railcars, filled to $25.17 \mathrm{MPa}$, on-site, with a third LHe tanker scheduled to arrive at KSC 24 hours after the scheduled launch, in the event of an abort/recycle. Typically the STS program will use about 60 percent of the helium delivered to the CCF, with the balance used by the CCAS ELV programs. 


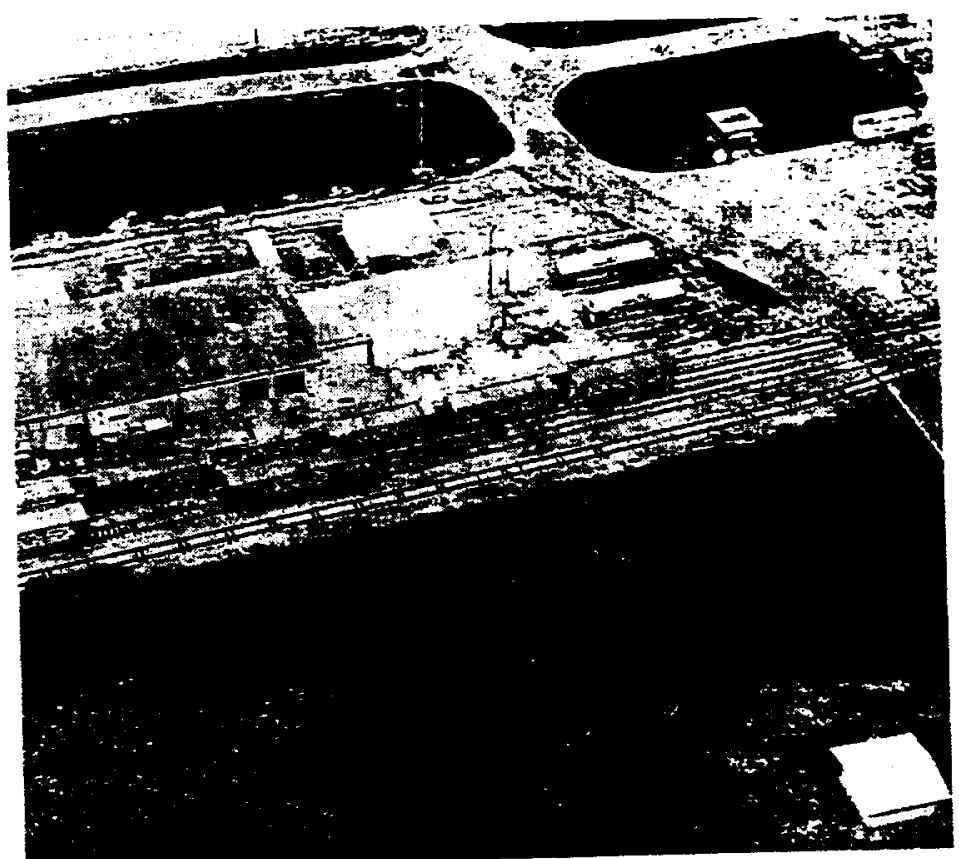

Figure 1. Aerial view of CCF liquid helium system (looking south).

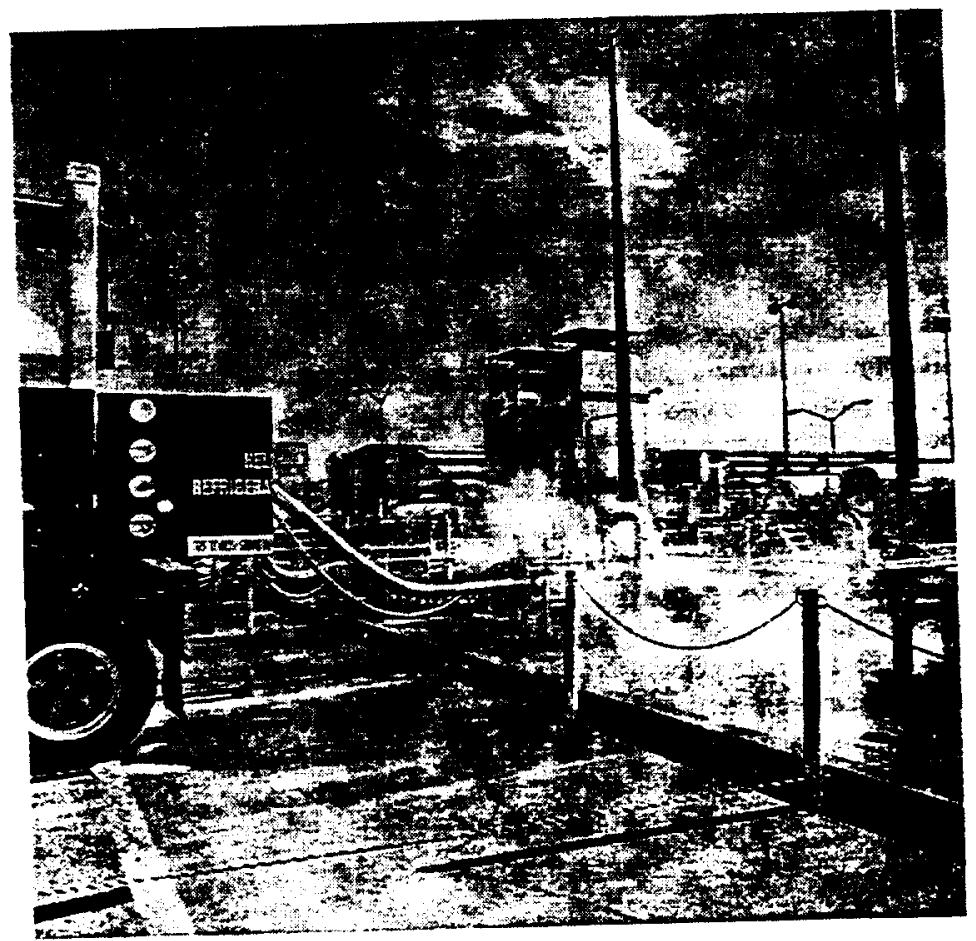

Figure 2. In-process off-loading of liquid helium from tankers at the CCF. 


\section{LHe STORAGE SYSTEM}

The second phase of the project, presently in design, will install a $227-\mathrm{m}^{3} \mathrm{LHe}$ storage system. Several other options of helium storage had been considered and evaluated in a life cycle cost analysis. Next to operating without LHe storage, as currently done, the analysis indicated that LHe storage was $\$ 373,000$ less expensive than the next best option over a 5-year period. Presently, KSC depends on the "on-time" delivery of two LHe tankers, with a third ready at the vendor plant in the event of an STS launch abort/recycle. Also, railcars are pressurized in preparation for an STS launch and are available if needed.

Concurrently to the procurement of the equipment needed for the first phase of the modification, procurement was initiated for two $113.5-\mathrm{m}^{3}$ LHe storage containers manufactured by Gardner Cryogenics, Inc. ${ }^{3}$ Delivered in May and June of 1998, respectively, these are the seventh and eighth LHe containers of this size built by the manufacturer. Each LHe storage container has an MAWP of $483 \mathrm{kPa}$ and an empty weight (including the piping skid) of $34,000 \mathrm{~kg}$. The container is $18.9 \mathrm{~m}$ long, $3.7 \mathrm{~m}$ wide, and $3.8 \mathrm{~m}$ high. The heat leak is guaranteed to be no more than 13.1 watts (i.e., 0.4 percent normal evaporation rate) when helium shielded, assuming a $29.4^{\circ} \mathrm{C}$ ambient temperature. The storage containers are currently configured to be helium shielded but can be reconfigured to be $\mathrm{LN}_{2}$ shielded. Each storage container is equipped with load cells and a weight-measuring system, allowing the amount of helium in the container to be monitored.

There are three routine operations (planned) involving the LHe storage containers. The first is off-loading LHe from the storage containers to supply the first phase LHe conversion system. It is uncertain the degree of usage that these containers will serve as the primary supply (rather than LHe tankers), since their original intent was for contingency supply for an STS launch abortrecycle. Instead of pressurizing the storage containers to $276 \mathrm{kPa}$ as done on the LHe tanker containers, a pressure of around $7 \mathrm{kPa}$ will attempt to be maintained as a target pressure.

In order to supply the existing system, a compressor/pump is necessary to boost the pressure to at least $241 \mathrm{kPa}$ (termed a booster compressor). The second operation involving the LHe storage containers is refilling, by transferring the liquid inventory from a tanker in order to replenish the stored LHe. It is critical for an efficient transfer/refill that the storage (i.e., receiving) containers be at as low a pressure as practical. So as to not vent the GHe displaced by the incoming liquid (filling the storage container) and the GHe generated from the pressure drop and heat leak into the liquid transfer line (between the tanker and storage containers), a compressor is also necessary to boost the GHe pressure from the storage container to $241 \mathrm{kPa}$. Finally, the storage containers must be depressurized on a regular/intermittent basis to remove boiled-off liquid, rather than vent the vapor. For this operation also, a compressor is necessary to supply the existing system. Presently, KSC plans to use several cold gas compressors capable of accepting LHe and/or GHe to serve as a booster compressor. This is an attractive option because it is (1) significantly less expensive than an "ambient temperature" compressor (e.g., most likely a rotary-screw type), (2) is expected to be reliable, and (3) does not require a large area to install or a large power supply. The second phase is planned to begin implementation next spring.

\section{CONCLUSIONS}

The LHe Conversion System at the CCF is believed to be the largest facility of its type in the US, perhaps the world. Future programs, such as the Evolved Expendable Launch Vehicle and the Reusable Launch Vehicle, are anticipated to each require an amount of helium comparable to that used by STS operations. A proven reliability would make the $\mathrm{CCF}$ the focal point for the helium supply for those future programs. ${ }^{6}$ 